\title{
Outcomes of Antibiotics in Adults with "Difficult to Treat" Asthma or the Overlap Syndrome
}

\author{
Fred A Wagshul' \\ Doris T Brown' \\ Nikki M Schultek ${ }^{2}$ \\ David L Hahn (D) ${ }^{2}$ \\ 'Lung Center of America, Dayton, $\mathrm{OH}$, \\ 45458, USA; ${ }^{2}$ Intracell Research Group, \\ Wake Forest, NC, USA
}

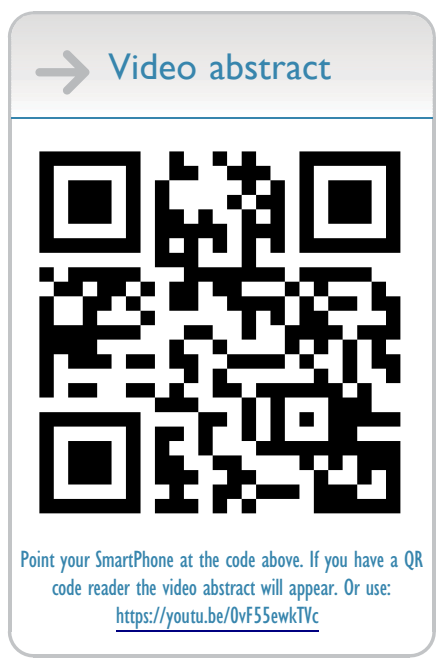

Correspondence: David L Hahn 5203 County Road ZZ, Dodgeville, WI, 53533, USA

Tel + I-608-234-3212

Email dlhahn@wisc.edu
Purpose: Macrolides are a recommended treatment option for severe asthma, but data for "difficult-to-treat" asthma, the asthma-COPD "overlap" syndrome, and treatment duration beyond one year are lacking. We present long-term data from community practice experience providing insights for practice and research.

Methods: We report data from (1) baseline (pre-treatment) chart review of antibiotic-treated asthma patients and (2) follow-up telephone interviews documenting severe exacerbations (NIH criteria), Asthma Control Test (ACT) scores, and asthma controller use at baseline and follow-up, analyzed using a "before-after" model.

Results: A total of 101 patients (mean age 55.6 years (Sd 16.8), 66 females) were included. None had ever taken high dose inhaled corticosteroids and 79 (78.2\%) were severely uncontrolled (ACT score $\leq 15$ ) before treatment. Coexisting COPD was present in $62(61.4 \%)$ patients. Azithromycin or azithromycin plus doxycycline was primarily prescribed with a median treatment duration of 12 months and median follow-up duration of 22 months. Severe exacerbations in the month before treatment occurred in $50.5 \%$ vs $17.8 \%$ at follow-up $(\mathrm{P}<0.0001)$. Mean ACT score increased from 12.2 to 20.6 $(\mathrm{P}<0.0001)$. The number of patients taking controller medications decreased $(\mathrm{P}<0.0001$ for inhaled corticosteroids; $\mathrm{P}<0.001$ for long-acting beta agonist/long-acting muscarinic antagonist; $\mathrm{P}<0.05$ for leukotriene receptor antagonists). Of the 79 severely uncontrolled patients, $51(64.6 \%)$ became controlled at follow-up, and of these 51, $27(52.9 \%)$ continued to take antibiotics while $24(47.1 \%)$ had discontinued antibiotics earlier yet remained controlled.

Conclusion: Antibiotic treatment may be beneficial in a significant proportion of "difficult to treat" asthma patients beyond one year, including some patients with the overlap syndrome and/or who fail to meet criteria for refractoriness.

Keywords: asthma, "difficult to treat" asthma, macrolides, tetracyclines, overlap syndrome, case series

\section{Plain Language Summary}

- Many patients with asthma encountered in community practice have uncontrolled asthma but are not necessarily refractory to inhaled steroids (called "difficult to treat" asthma). It is also common to encounter patients diagnosed with both asthma and COPD (called the "overlap" syndrome). Evidence indicates that these patients developed COPD as a consequence of severe asthma.

- Current guidelines recommending macrolide antibiotics for severe asthma do not apply to "difficult to treat" or "overlap" patients because these patient groups have not been included in clinical trials. 
- Results of this "before-after" report of antibiotics (macrolides and/or tetracyclines) prescribed to 101 patients with "difficult to treat" asthma, many of whom had the "overlap" syndrome, confirm that these patients can experience significant improvement in their asthma after treatment and should be included in future randomized clinical trials.

- A subgroup of patients in this report experienced prolonged improvement in their asthma symptoms that persisted long after completing a treatment course. This is inconsistent with a host-directed anti-inflammatory mechanism of action and rather suggests a pathogen-directed mechanism of action that should be further investigated.

\section{Introduction}

Azithromycin is included as a treatment option for severe refractory asthma in the Global Initiative for Asthma (GINA), ${ }^{1}$ European Respiratory Society/American Thoracic Society (ERS/ATS) ${ }^{2}$ and British Thoracic Society (BTS $)^{3}$ guidelines. ERS/ATS notes that benefits and safety beyond one year has not been determined. ERS/ATS also notes the lack of evidence for benefit in severe exacerbations. BTS notes that continued treatment should be guided by clinical response including exacerbation frequency, symptoms and quality of life and that breaks in therapy may be considered if desired outcomes are achieved. Guidelines do not describe mechanism of action (ie, immunomodulatory, anti-viral, or anti-microbial), which is unknown. These limitations illustrate some unanswered clinical and scientific questions.

Asthma and COPD are almost always studied in isolation. $^{4,5}$ No data are available on the $30 \%$ of chronic lung disease patients with the asthma-COPD overlap syndrome $(\mathrm{ACO})^{6}$ yet many patients encountered in community-based practice will have ACO. Prospective, populationbased epidemiologic studies indicate that ACO develops from asthma ${ }^{7}$ and is a severe form of asthma. ${ }^{8}$ Therefore, it is plausible to regard asthma and ACO as parts of the same natural history of obstructive lung disease. Management is also complicated by patient unwillingness to take steroid medications, inability to afford them or other characteristics associated with "difficult-to-treat" asthma. ${ }^{1}$ Macrolides have efficacy for severe asthma ${ }^{9,10}$ and smoking-associated COPD $^{11}$ but benefits in ACO patients have not been studied. Here, we report a practice-based case series of clinically diagnosed "difficult to treat" asthma patients, many with ACO, who elected chronic macrolide and/or tetracycline treatment and were followed-up 2 years on average. The clinician whose experience we report here began adopting antibiotic treatment for asthma several decades ago based on reported efficacy of macrolides for the atypical infections Mycoplasma pneumoniae (Mp) and Chlamydia pneumoniae (Cp). ${ }^{12}$ Macrolide and/or tetracycline antibiotics were chosen because of their effectiveness against both $\mathrm{Mp}$ and $\mathrm{Cp}$. The purpose of this report is two-fold: (1) to report some positive results that may be of interest to other treating clinicians and (2) to underscore some unanswered questions that should be addressed through further research.

\section{Methods}

This retrospective observational study uses a "before-after" analysis model ${ }^{13}$ to report results of prescribing long-term antibiotics for asthma. The board-certified pulmonologist (FAW) whose US mid-western practice is reported here followed procedures in accordance with the Helsinki Declaration as revised in $2013^{14}$ because he had no access to a formal ethics committee. Based on the University of Wisconsin-Madison Human Subjects Institutional Review Board's QI/PE Decision Tree (V4-18-16), this project met criteria as quality improvement. An employee of the practice (DTB) obtained all data and one of the coauthors (DLH) analyzed it under a HIPAA-compliant data sharing agreement. All patients with a diagnosis of asthma first encountered between January 15, 2017 and October 15, 2019 (baseline) were included and were interviewed between April and October 2020 (follow-up). Baseline medical record data included demographics, co-existing lung diagnoses (eg, COPD), asthma controller medications and prescribed antibiotics. Commercial laboratory serologic testing results for Chlamydia pneumoniae (Cp) and Mycoplasma pneumoniae (Mp) were recorded. $\mathrm{Cp}$ microimmunofluorescence (MIF) test results were provided as $<1: 64,1: 64,1: 128,1: 512$, etc. Mp enzyme immunoassay (EIA) optical density (OD) results were reported as $\leq 0.9$ (negative), 0.91-1.09 (equivocal) and $\geq 1.1$ (positive). Pulmonary function test (PFT) results were recorded when present.

Follow-up phone interview data included (1) severe exacerbations occurring in the past 4 weeks (steroid bursts $>3$ days for asthma and/or hospitalization for asthma ${ }^{15}$ ), (2) Asthma Control Test (ACT) ${ }^{16}$ scores (past 4 weeks), and (3) change in quality of life using an ad hoc 7-item scale (very much worse to very much better). Comparable baseline exacerbation and ACT score data were obtained retrospectively. To aid in recall, medical record information was shared with patients as needed to jog memory for these baseline questions. ACT scores were categorized as controlled (score $\geq 20$ ), suboptimally controlled (ACT 
score 16-19), or severely uncontrolled (ACT score $\leq 15$ ). Data on age of asthma onset, currently administered asthma controller medication, maximum ever doses of asthma controller medication, length of antibiotic treatment, whether antibiotics were still being taken and antibiotic side effects (if any) were also recorded during the follow-up interviews. Inhaled corticosteroid medication doses were classified as Low, Medium or High based on the Global Initiative for Asthma (GINA) Global Strategy for Asthma Management and Prevention, 2018, page 45, Box 3-6 (available from www.ginaasthma.org). The use of long-acting beta-agonists and/or long-acting muscarinic antagonists (LABA/LAMA) was recorded as present/ absent without recording the specific dose, brand or formulation. Additional interview data included whether first asthma symptoms had been associated with an acute lower respiratory tract illness. This recalled association has been termed the "infectious asthma" (IA) syndrome ${ }^{17}$ or AAWI (asthma associated with infection). ${ }^{18}$

Descriptive statistics are presented as mean (Standard deviation) and/or median and 25th to 75 th percentile. Baseline to follow up differences for binary outcomes were evaluated by Fisher's Exact test $(2 \times 2$ tables $)$ or the Chi-square test (nxn tables). Continuous variables were compared using the paired $t$-test (for normally distributed data) or the Mann-Whitney $U$-test (for non-normally distributed data). A two-sided p-value $<0.05$ was considered statistically significant.

\section{Results}

Table 1 presents patient characteristics. Patient age, age of asthma onset and asthma duration ranges were broad, almost two-thirds were female, most were never- or exsmokers, and one in six patients was from out of state (often self-referred specifically to explore the possibility of antibiotic treatment). Sixty percent of patients reported having had one or more asthma exacerbations in the past year. Notably, 62 (61.4\%) had a clinical diagnosis of coexisting COPD. ACO is supported by objective evidence for airflow limitation and/or decreased diffusion capacity in the subgroup with post-bronchodilator PFT and/or single-breath diffusing capacity of the lung for carbon monoxide (DLCO) data: 25 of 67 with lung function data had a post-bronchodilator FEV1/FVC ratio $<70 \%$ and/or DLCO $<80 \%$ predicted, and $21(84 \%)$ of these 25 had a clinical diagnosis of COPD. The presence of a high proportion of ACO patients in this asthma cohort may explain the blunted effect of bronchodilator on FEV1 reversibility in the 50 patients (43 with a COPD diagnosis) who had a documented post-bronchodilator PFT (Table 1).

Also notable are the $77(77 \%)$ patients who stated that their asthma first became symptomatic during an acute lower respiratory illness $\left(\mathrm{IA}^{17}\right.$ or AAWI ${ }^{18}$ ). On serologic testing there were elevated titers of anti-Cp IgG $\geq 1: 64$ and/ or $\operatorname{IgA} \geq 1: 16$ present in 25 (24.8\%) patients. Mp IgM and/ or $\operatorname{IgG}$ positivity $(\mathrm{OD} \geq 1.1)$ was present in $67(66.3 \%)$. Of $75 \mathrm{Cp} / \mathrm{Mp}$ biomarker-positive patients, 59 (78.7\%) reported infectious asthma. Of 23 patients who denied infectious asthma syndrome, 16 (69.6\%) were also $\mathrm{Cp} /$ Mp biomarker positive.

Table 2 presents the antibiotic treatment parameters of the study cohort. Most patients were treated with azithromycin, with or without doxycycline or minocycline, for a median duration of one year. Doses were $250 \mathrm{mg}$ azithromycin once daily, $500 \mathrm{mg}$ clarithromycin twice daily and $100 \mathrm{mg}$ for both doxycycline and minocycline twice daily. Prescription for a tetracycline antibiotic was not associated with $\mathrm{Mp}$ biomarker positivity $(\mathrm{P}=0.51)$. Nineteen patients reported side effects, mostly mild to moderate. Seven patients discontinued antibiotic treatment due to side effects (GI upset in six, rash in one) and three were changed to a different antibiotic.

Table 3 compares baseline to follow-up asthma controller medications, ACT test score results, and severe exacerbations. All the major categories of asthma controller medication (inhaled steroids, LABA, LAMA and leukotriene receptor antagonist) were taken significantly $(p<0.05$ to $p<0.0001)$ less often at follow-up compared to baseline. ACT mean and median scores increased from baseline to follow-up well beyond the minimum important difference (MID) of 3 points. ${ }^{19}$ Table 3 also presents patients' assessments of how their quality of life (QOL) changed from baseline to follow-up. QOL was much better or very much better in $67(66.3 \%)$ and higher QOL scores correlated with higher ACT change scores $(\mathrm{r}=0.712$, $\mathrm{P}<0.0001$ ).

Of the 79 severely uncontrolled asthma patients at baseline, 51 (64.6\%) became controlled, 14 (17.7\%) became sub optimally controlled and $14(17.7 \%)$ remained severely uncontrolled during antibiotic treatment. Of the 51 severely uncontrolled patients achieving control after antibiotic treatment, 27 (52.9\%) were continuing to take antibiotics at follow-up. A surprising finding was that 24 (47.1\%) had actually discontinued antibiotics earlier and remained controlled off all antibiotics for a mean of 16.8 months (Sd 12.0, median 13.5, 25\%ile-75\%ile 7-27.5). 
Table I Asthma Patient Characteristics at Baseline (Pre-Antibiotic Treatment)

\begin{tabular}{|c|c|}
\hline Number of asthma patients audited & 101 \\
\hline Age (years), mean (Sd) & $55.6(16.8)$ \\
\hline Median, $25 \%$ ile- $75 \%$ ile & $59(46-66)$ \\
\hline Sex, no. $M / F(\% F)$ & $35 / 66(65.3)$ \\
\hline \multicolumn{2}{|l|}{ Smoking status, $\mathrm{n}(\%)$} \\
\hline Never & $62(61.4)$ \\
\hline Past & $33(32.7)$ \\
\hline Current & $6(5.9)$ \\
\hline (Self) referred from out of state, $n(\%)$ & $17(16.8)$ \\
\hline Age of asthma onset (years), ${ }^{*}$ mean $(S d)$ & $33.9(20.7)$ \\
\hline Median, $25 \%$ ile-75\%ile & $32.8,19-49$ \\
\hline Child-onset ( $\leq$ age 12$), \mathrm{n}(\%)$ & $18(18)$ \\
\hline Adolescent-onset (12-SI8), n (\%) & $6(6)$ \\
\hline Adult onset $(\geq 18), \mathrm{n}(\%)$ & $76(76)$ \\
\hline Asthma symptom duration (years), $*$ mean $(\mathrm{Sd})$ & $20.5(16.9)$ \\
\hline Median, $25 \%$ ile-75\%ile & $17.5,6-30$ \\
\hline Co-existing COPD diagnosis, $n(\%)$ & $62(6 I .4)$ \\
\hline Asthma symptoms began after an acute respiratory illness, ${ }^{*} \mathrm{n}(\%)$ & $77(77)$ \\
\hline \multicolumn{2}{|l|}{ Number of exacerbations in year prior to baseline, $\mathrm{n}(\%)^{*}$} \\
\hline 0 & $40(40)$ \\
\hline 1 & $44(44)$ \\
\hline$\geq 2$ & $16(16)$ \\
\hline \multicolumn{2}{|l|}{ Maximal Asthma Treatments (ever) } \\
\hline Taking inhaled corticosteroids (ICS), n (\%) & $83(82.2)$ \\
\hline Low dose ICS, $\mathrm{n}$ & $80(79.2)$ \\
\hline Medium dose ICS, n & $3(3.0)$ \\
\hline High dose ICS, $\mathrm{n}$ & $0(0)$ \\
\hline Taking LABA and/or LAMA, n (\%) & $82(81.2)$ \\
\hline Taking Leukotriene receptor antagonist, n (\%) & $72(71.3)$ \\
\hline Taking a biologic, n (\%) & $5(5.0)$ \\
\hline Taking theophylline, n (\%) & $\mathrm{I}(\mathrm{I} .0)$ \\
\hline Taking chronic oral corticosteroids, n (\%) & $0(0)$ \\
\hline Pre-bronchodilator spirometry obtained, n (\%) & $74(73.3)$ \\
\hline FVC\%predicted, mean (Sd) & $85.2(14.5)$ \\
\hline Median, $25 \%$ ile- $75 \%$ ile & $86,73-96$ \\
\hline FEVI\%predicted, mean (Sd) & $80.9(22.2)$ \\
\hline Median, $25 \%$ ile- $75 \%$ ile & $87.5,69-97$ \\
\hline FEVI/FVC\%predicted, mean (Sd) & $73.2(13.6)$ \\
\hline Median, 25\%ile-75\%ile & $76,67-82$ \\
\hline Diffusing capacity (DLCO) obtained, n (\%) & $62(6 I .4)$ \\
\hline Diffusing capacity (DLCO), mm/min/mmHg\%predicted, mean (Sd) & $93.2(31.9)$ \\
\hline Median, $25 \%$ ile- $75 \%$ ile & $91,74-111$ \\
\hline DLCO<80\%predicted, n (\%) & $18(29.0)$ \\
\hline Post-bronchodilator spirometry obtained, n (\%) & $50(49.5)$ \\
\hline FVC\%predicted, mean (Sd) & $86.6(14.5)$ \\
\hline Median, $25 \%$ ile-75\%ile & $89,77-98$ \\
\hline
\end{tabular}

(Continued) 
Table I (Continued).

\begin{tabular}{|c|c|}
\hline FEVI\%predicted, mean (Sd) & $79.7(2 \mid .3)$ \\
\hline Median, $25 \%$ ile-75\%ile & $86,68-95$ \\
\hline Change from pre-bronchodilator FEVI\%predicted, \% (Sd) & $6.5(13.3)$ \\
\hline Median change, $25 \%-75 \%$ ile, $\%$ & $4.2,1-11.4$ \\
\hline Met ATS criteria $\nmid$ for reversible airway obstruction, n (\%) & $9(18)$ \\
\hline FEVI/FVC\%predicted, mean (Sd) & $71.3(13.0)$ \\
\hline Median, $25 \%$ ile-75\%ile & $74.5,67-80$ \\
\hline FEVI/FVC < $70 \%, \mathrm{n}(\%)$ & $16(32.0)$ \\
\hline \multicolumn{2}{|l|}{ Chlamydia pneumoniae $\left(C_{p}\right)$ biomarkers } \\
\hline \multicolumn{2}{|l|}{ Cp IgG microimmunofluorescence (MIF) titer, $n$ (\%)* } \\
\hline$<1: 64$ & $80(80)$ \\
\hline $\mathrm{I}: 64$ & $4(4)$ \\
\hline $1: 128$ & $8(8)$ \\
\hline $1: 256$ & $8(8)$ \\
\hline \multicolumn{2}{|l|}{ Cp IgA MIF titer, $n(\%)^{*}$} \\
\hline$<1: 16$ & $94(94)$ \\
\hline $1: 16$ & $2(2)$ \\
\hline $1: 32$ & $\mathrm{I}(\mathrm{I})$ \\
\hline $\mathrm{I}: 64$ & I (I) \\
\hline $\mathrm{I}: 128$ & $2(2)$ \\
\hline Any $C_{p} \lg G \geq 1: 64$ and/or $C_{p} \lg A \geq 1: 16, n(\%)$ & $25(24.8 \%)$ \\
\hline \multicolumn{2}{|l|}{ Mycoplasma pneumoniae (Mp) biomarkers } \\
\hline \multicolumn{2}{|l|}{ Mp IgM enzyme immunoassay (EIA) optical density (OD), $n(\%)^{* *}$} \\
\hline$\leq 0.9$, negative & $80(80.8)$ \\
\hline $0.91-1.09$, equivocal & $5(5.1)$ \\
\hline$\geq I$.I, positive & $14(14.1)$ \\
\hline \multicolumn{2}{|l|}{ Mp lgG EIA OD, $n(\%)^{*}$} \\
\hline$\leq 0.9$, negative & $23(23)$ \\
\hline $0.91-1.09$, equivocal & $15(15)$ \\
\hline$\geq I . I$, positive & $62(62)$ \\
\hline Any $M p \lg M \geq I . I$ and/or $M p \lg G \geq I$.I, n (\%) & $67(66.3)$ \\
\hline
\end{tabular}

Notes: ${ }^{*} n=100$, I case missing data. ${ }^{*} n=99,2$ cases missing. $\nmid F E V I$ variation of $\geq 12 \%$ and $>200 \mathrm{~mL}$.

Figure 1 presents individual patient results for ACT scores at baseline and follow-up. Of note are the 14 (13.9\%) of 101 patients with follow-up ACT scores of 25 , meaning that they denied all asthma-related symptoms and were using no rescue medications. Of these 14 , ten had been severely uncontrolled at baseline, and six were no longer taking any antibiotics, yet they remained asthma symptom free (four of six were antibiotic free for between 13 and 32 months at the time of follow-up, and two were antibiotic free for less than 12 months). Further analysis of these six patients revealed that they were taking no asthma controller medications (ICS, LABA or LAMA), and only one of them was taking LRA. None of these patients reported any exacerbations at follow-up. Five reported that their quality of life (QOL) was very much better and one reported that QOL was much better. Five of the six patients reported that their asthma began after an acute respiratory illness and five (four with and one without infectious onset) also had one or more positive biomarkers for $\mathrm{Cp}$ or Mp. Two had a coexisting diagnosis of COPD, one reported child-onset asthma, and five reported adultonset asthma. Duration of antibiotic treatment had ranged from 9 to 16 months (median 12.5 months). Treatment consisted of azithromycin in all six, combined with doxycycline in four.

Compared to the 39 non-ACO patients, the $62 \mathrm{ACO}$ patients had comparable improvements in exacerbations, ACT change scores and QOL at follow-up, and comparable baseline ICS/LABA use. However, follow-up ICS/ LABA use was greater in ACO patients $(\mathrm{P}=0.057$ for 
Table 2 Antibiotic Treatment Characteristics

\begin{tabular}{|c|c|}
\hline Antibiotic(s) prescribed, n (\%) & $101(100)$ \\
\hline Azithromycin alone & $31(30.7)$ \\
\hline Clarithromycin alone & $2(2.0)$ \\
\hline Azithromycin and clarithromycin & $2(2.0)$ \\
\hline Doxycycline alone & $6(5.9)$ \\
\hline Minocycline alone & $2(2.4)$ \\
\hline Azithromycin and doxycycline & $49(48.5)$ \\
\hline Clarithromycin and doxycycline & $7(6.9)$ \\
\hline Azithromycin and minocycline & $2(2.4)$ \\
\hline Antibiotic treatment duration (months), mean (Sd) & $12.8(7.4)$ \\
\hline Median, $25 \%$ ile- $75 \%$ ile & $12,8-16$ \\
\hline Months elapsed from baseline (pre-treatment) to follow-up, mean (Sd) & $24.4(11.3)$ \\
\hline Median, $25 \%$ ile- $75 \%$ ile & $22,14-35$ \\
\hline \multicolumn{2}{|l|}{ Continuing to take antibiotics at follow-up, n (\%) } \\
\hline Yes & $52(51.5)$ \\
\hline No & $49(48.5)$ \\
\hline Number of side effects reported at follow-up visits, $\mathrm{n}$ (\%) (in 19 patients) & $22(21.8)$ \\
\hline Mild, n (\%) & $16(15.8)$ \\
\hline Moderate, n (\%) & $5(5.0)$ \\
\hline Severe, n (\%) & $\mathrm{I}(\mathrm{I} .0)$ \\
\hline Discontinued due to side effect, $\mathrm{n}(\%)$ & $7(6.9 \%)$ \\
\hline
\end{tabular}

ICS and $\mathrm{P}=0.034$ for LABA) compared to the non-ACO patients. Furthermore, increased follow-up ICS/LABA use was even more significant in the 21 patients with ACO confirmed by post-bronchodilator $\mathrm{FEV} 1 / \mathrm{FVC}<70 \%$ and/or DLCO $<80 \%$, compared to other ACO patients $(\mathrm{P}=0.031$ for ICS and $\mathrm{P}=0.014$ for LABA). Lastly, within the group of 74 patients with available post-bronchodilator results there were no differences in any of these outcomes when patients meeting ATS reversibility criteria were compared to the remainder.

\section{Discussion}

The data from this large case series confirm that "difficultto-treat" asthma patients can experience improvement after antibiotics. None of the patients reported here would have been eligible for the trials upon which the macrolide guidelines are based because they had not failed Step 4 or 5 GINA treatment. These observations strongly support the need to include "difficult to treat" (ie, severely uncontrolled, but not necessarily refractory) asthma patients in future macrolide trials to better understand the depth and breadth of the asthma patient population likely to respond to macrolides or other antibiotics.

Our series contained a high prevalence (61.4\%) of a co-existing clinical diagnosis of COPD (the overlap syndrome or $\mathrm{ACO}^{6}$ ). Prevalence of $\mathrm{ACO}$ in the general population of patients with obstructive airways diseases has been estimated at around $30 \%$ for the age composition of this patient series. ${ }^{6}$ ACO is characterized by frequent exacerbations, hospitalizations, poor quality of life and high healthcare costs; it also appears to represent a form of severe asthma that has progressed to fixed airflow obstruction. ${ }^{7,8,20}$ ACO has been systematically excluded from virtually all treatment efficacy studies of asthma and COPD., 4,21 A previous "beforeafter" community-based study reported that asthma patients with ACO responded less well to antibiotics than "pure" asthma patients. ${ }^{13}$ Our data also suggest that ACO patients may respond less well than nonACO asthma patients, as indicated by a requirement for greater continued use of ICS/LABA. Superior antibiotic effectiveness in early disease (eg, "pure" asthma) compared to later disease (eg, ACO) is consistent with a chlamydial pathogenesis in which later stages of infection are associated with irreversible scarring that is not as amenable to antibiotic treatment. ${ }^{13}$

This case series group contained a high proportion (77\%) of patients who reported that their asthma began after an acute respiratory illness (IA, AAWI). Prevalence of the IA/AAWI syndrome was $45 \%$ in an unselected 
Table 3 Clinical Outcomes After Taking Long-Term Antibiotics for Asthma: Controller Medication Use, Asthma Control, Severe Exacerbations and Self-Rated Quality of Life Improvement

\begin{tabular}{|c|c|c|c|}
\hline Outcome & Baseline & Follow-Up & P-value* \\
\hline \multicolumn{4}{|l|}{ Asthma Treatments } \\
\hline Taking inhaled corticosteroids (ICS), n (\%) & $69(68.3)$ & $35(34.7)$ & $<0.0001$ \\
\hline Low dose ICS, $n$ & $67(66.3)$ & $34(33.7)$ & $<0.000$ I \\
\hline Medium dose ICS, n & $2(2.0)$ & I ( $(1.0)$ & 0.99 \\
\hline High dose ICS, $\mathrm{n}$ & $0(0)$ & $0(0)$ & I \\
\hline Taking LABA and/or LAMA, n (\%) & $70(69.3)$ & $45(44.6)$ & $<0.001$ \\
\hline Taking Leukotriene receptor antagonist, n (\%) & $63(62.4)$ & $48(47.5)$ & $<0.05$ \\
\hline Taking a biologic, n (\%) & $I(1.0)$ & $\mathrm{I}(\mathrm{I} .0)$ & I \\
\hline Taking theophylline, $\mathrm{n}(\%)$ & $\mathrm{I}(\mathrm{I} .0)$ & $2(2.0)$ & 0.99 \\
\hline Taking chronic oral corticosteroids, n (\%) & $0(0)$ & $0(0)$ & I \\
\hline Asthma Control Test, mean score (Sd) & $12.2(4.5)$ & $20.6(3.9)$ & $<0.000 I^{* *}$ \\
\hline Median, $25 \%$ ile- $75 \%$ ile & II (9-15) & $21(19-24)$ & $<0.0001 \dagger$ \\
\hline Well controlled (ACT score $\geq 20), n(\%)$ & $10(9.9)$ & $71(70.3)$ & $<0.0001$ \\
\hline Sub-optimally controlled (16-19), n (\%) & $12(11.9)$ & $\mathrm{I}(\mathrm{I} 5.8)$ & 0.004 \\
\hline Severely uncontrolled ( $\leq 15), \mathrm{n}(\%)$ & $79(78.2)$ & $14(13.9)$ & $<0.0001$ \\
\hline One or more severe exacerbations in the previous 4 weeks, $n(\%)^{\pi}$ & $51(50.5)$ & $18(17.8)$ & $<0.0001$ \\
\hline One or more oral steroid bursts $>3 \mathrm{~d}, \mathrm{n}(\%)$ & $48(47.5)$ & $18(17.8)$ & $<0.0001$ \\
\hline One or more hospitalizations for asthma, $n$ (\%) & $19(18.8)$ & $0(0)$ & $<0.0001$ \\
\hline \multicolumn{4}{|l|}{ Quality-of-life improvement self-assessment at follow-up } \\
\hline Unchanged & & $13(12.9)$ & \\
\hline Some better & & $21(20.8)$ & \\
\hline Much better & & $26(25.7)$ & \\
\hline Very much better & & $4 \mid(40.6)$ & \\
\hline
\end{tabular}

Notes: *Fishers Exact test unless indicated otherwise. ${ }^{* *}$ Paired $t$-test. $†$ Mann-Whitney $U$-test. "Subcategories sum to $>73$ because a severe exacerbation may include both subcategories.

community-based primary care practice. ${ }^{17}$ The population prevalence of IA/AAWI is unknown because clinicians are not trained to routinely elicit or record this type of patient history systematically. Over 30 years ago, studies documented that acute respiratory illnesses often preceded chronic lung diseases, including asthma, in both children and adults. ${ }^{22-24}$ A 2011 population-based epidemiologic study reported that acute lower respiratory illnesses are strongly (odds ratio 7.2) associated with developing asthma. ${ }^{25}$ Clinicians and researchers would be well advised to document the presence/absence of IA/AAWI to determine whether this characteristic has clinical utility in predicting who will/will not respond to antibiotic treatment for asthma.

Macrolide mechanism of action in asthma is unknown and controversial. Macrolides have both pathogen- and host-directed anti-inflammatory activities that could explain, separately or together, macrolide effects in asthma. ${ }^{26}$ Macrolides target cells of both the innate and adaptive immune systems, and immunomodulatory effects appear to be particularly effective in attenuating neutrophilmediated inflammation. ${ }^{26}$ Clinical benefits of macrolides in severe asthma are not limited to neutrophilic asthma, however, but accrue also to eosinophilic asthma. ${ }^{9,27}$ Tetracyclines also have non-antibiotic pleiotropic effects. ${ }^{28}$ Some patients in our cohort achieved good control that persisted after stopping antibiotics (Figure 1). This clinical response is inconsistent with a host-directed immunomodulatory mechanism of action, suggesting pathogen-based etiology and the need to further investigate antimicrobial mechanisms of action. The commercially obtained $\mathrm{Cp}$ and Mp biomarker results have significant limitations and did not predict treatment response (data not presented). Cp IgG titers below 1:64 (ie, 1:16 and 1:32) are considered seropositive but were not reported by the company. The prevalence of $\mathrm{Cp} \mathrm{IgG}$ seropositivity was well below the $>50 \%$ that has been reported for all adult populations worldwide ${ }^{29}$ and the high prevalence of Mp IgM positivity is unlikely valid since 


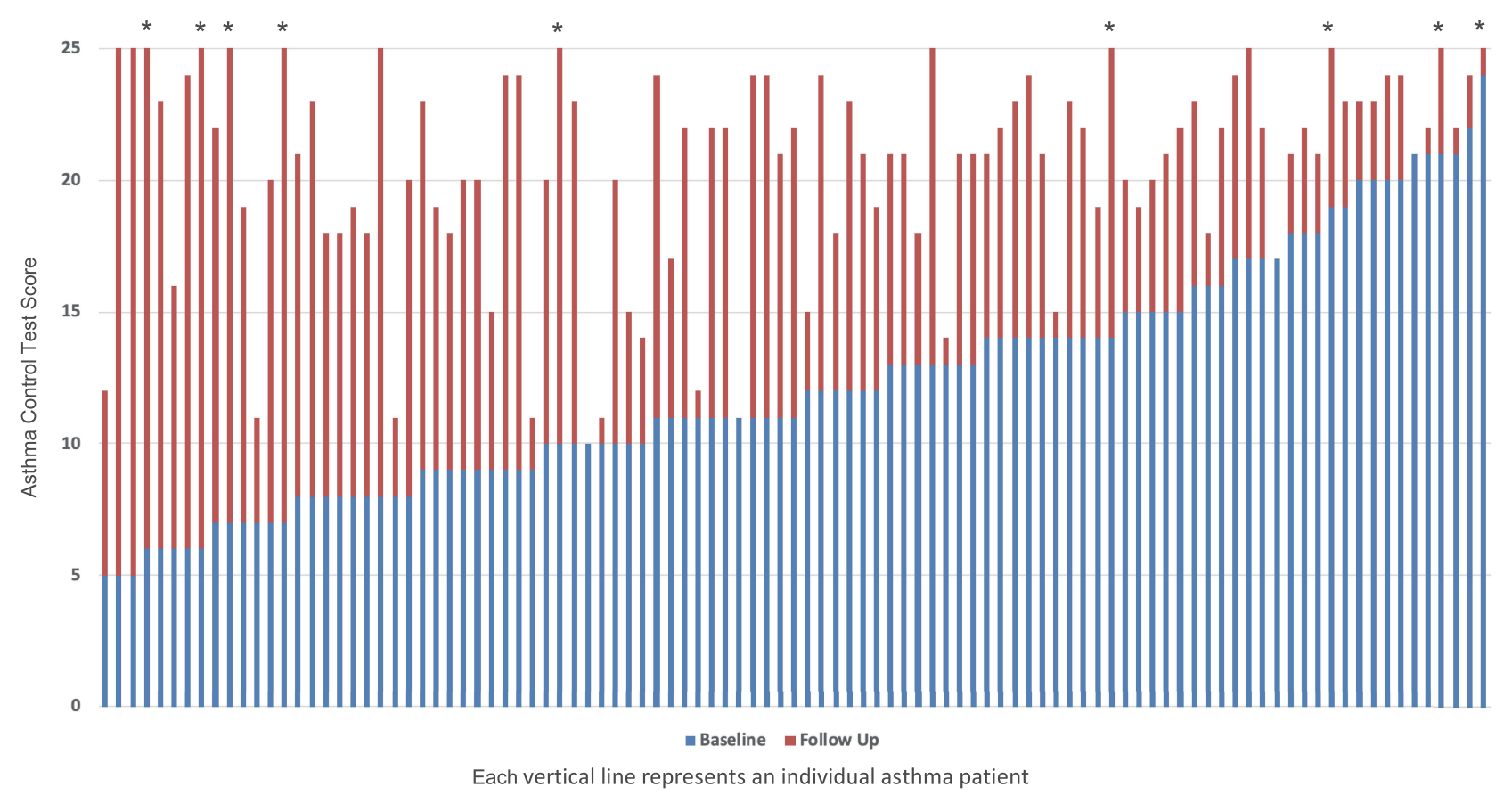

Figure I Asthma Control Test (ACT) scores (Y-axis) for individual patients (X-axis) at baseline (before antibiotic treatment: blue bars) and at follow-up (red bars). Asterisks $(*)$ indicate patients with follow-up ACT scores of 25 who are no longer taking antibiotics.

IgM indicates acute infection and is associated with asthma exacerbations, while most patients were stable when evaluated. ${ }^{30}$ Importantly, no validated serologic criteria for chronic $\mathrm{Cp}$ or Mp infection currently exist. ${ }^{31}$ Thus, the commercially determined $\mathrm{Cp}$ and $\mathrm{Mp}$ biomarker levels reported here probably have a limited clinical relevance to this study.

Other limitations include recording (medical record) and recall (interview) bias. We attempted to mitigate recall bias by sharing medical record information with patients to aid in recall of events prior to baseline. Clinical diagnoses of asthma were not systematically verified by PFTs. One-third of patients with physiciandiagnosed asthma may possibly be over diagnosed, but such overdiagnosis would apply more to mild than to severely symptomatic patients. ${ }^{32}$ COPD diagnosis was supported by objective evidence for airflow limitation and/or decreased diffusion capacity in the subgroup with lung function data, lending some credence to that clinical diagnosis. The QOL measure was an ad hoc score, not a previously validated instrument. QOL results were significantly and positively associated with ACT score changes, however. We did not record exacerbations for the year preceding the follow-up interview, precluding the possibility of estimating changes in asthma exacerbation rates. Instead, we recorded severe exacerbation prevalence in the 4 -week time periods prior to baseline and follow-up for each patient. Some baseline patient encounters may have occurred during an ongoing acute exacerbation and decreased exacerbation prevalence in that group at follow-up would be expected as part of the natural history of the disease. Most patients were first encountered when they were stable but symptomatic, however, and presence of baseline exacerbations was not associated with ACT score changes, ACT categories or QOL at follow-up (data not presented), implying that baseline exacerbations were not the sole explanation for improvements in the other outcomes. Also, the significant decrease in asthma controller medication use that accompanied the improvements supports the likelihood that the antibiotics caused the clinical improvement. There was no control group to help assess the role of temporal trends in asthma exacerbations and control. We cannot rule out that improvement occurred by chance or by the natural history of asthma, though given the large series this is unlikely. It is well established that adult asthma patients, particularly those with long-standing severe asthma such as those reported here, are highly unlikely to experience profound asthma remission within the one or two years of follow-up as in our cohort. 
This report raises some research questions and offers some possible answers: What patients are good candidates for antibiotic treatment? Future RCTs should include patients with severely uncontrolled asthma, including those with the overlap syndrome, irrespective of whether they are refractory to ICS. What antibiotic, or combination of antibiotics, is (are) optimal? Trials in Chlamydia-associated reactive arthritis indicate that double antibiotic treatment (azithromycin plus rifampin, doxycycline plus rifampin) is superior to placebo $^{33}$ or to azithromycin alone. ${ }^{34}$ No randomized trials to date have compared azithromycin to combination antibiotic treatment for asthma. Such trials are warranted because Cp biology resembles that of tuberculosis more than it resembles the biology of typical respiratory pathogens, and thus optimal eradication of Cp might require multiple antibiotics, as for tuberculosis. Should antibiotics be given continuously, intermittently, or as a limited treatment? Some of the patients in this case series had prolonged remissions after time-limited treatment, whereas others opted for ongoing administration. Future trials should include post-treatment observation periods. What is the underlying mechanism (s) of action? Cp-specific IgE, ${ }^{35,36}$ sensitive and specific $\mathrm{Cp} \quad \mathrm{IgA}$ enzyme-linked immunosorbent assays (ELISAs) $^{37,38}$ and Mp Community-Acquired Respiratory Distress Syndrome (CARDS) toxin antibodies, ${ }^{39}$ available only from research laboratories, are desirable candidates as infection biomarkers and should be considered for inclusion in future randomized clinical trials.

\section{Conclusion}

Our results support guideline recommendations that clinical response should guide continued macrolide treatment, with breaks in therapy being considered if/when the desirable clinical outcome occurs. ${ }^{3}$ Our results extend beyond the guidelines, demonstrating that benefits may accrue beyond one year, even in patients who have not received a trial of GINA Step 4-5 treatment and in patients with the overlap syndrome. ${ }^{40}$ Our results also showed that in a severely uncontrolled asthma cohort, the disease can go into prolonged clinical remission after long-term antibiotics. All these observations warrant further research.

\section{Abbreviation}

AAWI, asthma associated with infection syndrome; ACO, asthma-chronic obstructive pulmonary disease overlap syndrome; ACT, Asthma Control Test; COPD, chronic obstructive pulmonary disease; $\mathrm{Cp}, \quad$ Chlamydia pneumoniae; DLCO, single-breath diffusing capacity of the lung for carbon monoxide; EIA, enzyme immunoassay; ELISA, enzyme-linked immunosorbent assay; GINA, Global Initiative for Asthma; IA, infectious asthma syndrome; ICS, inhaled corticosteroid; IgA, IgE, IgM, IgG, immunoglobulins A, E, M and G, respectively; LABA/ LAMA, long-acting beta agonist/long-acting muscarinic antagonist; MID, minimum important difference; Mp, Mycoplasma pneumoniae; CARDS toxin, CommunityAcquired Respiratory Distress Syndrome toxin; OD, optical density; PFT, pulmonary function test; QOL, quality of life.

\section{Disclosure}

The authors report no conflicts of interest in this work. Atopic Medical, Inc. provided support for chart review.

\section{References}

1. GINA. Difficult-to-treat and severe asthma in adolescent and adult patients: diagnosis and management. 2019. Available from: https:// ginasthma.org/severeasthma/. Accessed June 20, 2020.

2. Holguin F, Cardet JC, Chung KF, et al. Management of severe asthma: a European Respiratory Society/American Thoracic Society guideline. Eur Respir J. 2020;55(1):1900588. doi:10.1183/ 13993003.00588-2019

3. Smith D, Du Rand IA, Addy C, et al. British Thoracic Society guideline for the use of long-term macrolides in adults with respiratory disease. BMJ Open Respir Res. 2020;7(1):e000489. doi:10.1136/ bmjresp-2019-000489

4. Travers J, Marsh S, Williams M, et al. External validity of randomised controlled trials in asthma: to whom do the results of the trials apply? Thorax. 2007;62:219-223. doi:10.1136/thx.2006.066837

5. Travers J, Marsh S, Caldwell B, et al. External validity of randomised controlled trials in COPD. Respir Med. 2007;101:1313-1320. doi:10.1016/j.rmed.2006.10.011

6. Gibson PG, Simpson JL. The overlap syndrome of asthma and COPD: what are its features and how important is it? $B M J$. 2009;64:728-735. doi:10.1136/thx.2008.108027

7. Silva GE, Sherrill DL, Guerra S, Barbee RA. Asthma as a risk factor for COPD in a longitudinal study. Chest. 2004;126:59-65. doi: $10.1378 /$ chest.126.1.59

8. de Marco R, Marcon A, Rossi A, et al. Asthma, COPD and overlap syndrome: a longitudinal study in young European adults. Eur Respir J. 2015;46(3):671-679. doi:10.1183/09031936.00008615

9. Gibson PG, Yang IA, Upham JW, et al. Effect of azithromycin on asthma exacerbations and quality of life in adults with persistent uncontrolled asthma (AMAZES): a randomised, double-blind, placebo-controlled trial. Lancet. 2017;390(10095):659-668. doi:10.1016/S0140-6736(17)31281-3

10. Gibson PG, Yang IA, Upham JW, et al. Efficacy of azithromycin in severe asthma from the AMAZES randomised trial. ERJ Open Res. 2019;5(4):4. doi:10.1183/23120541.00056-2019

11. Albert RK, Connett J, Bailey WC, et al. Azithromycin for prevention of exacerbations of COPD. N Engl J Med. 2011;365(8):689-698. doi:10.1056/NEJMoa1104623

12. Kraft M, Cassell GH, Pak J, Martin RJ. Mycoplasma pneumoniae and Chlamydia pneumoniae in asthma: effect of clarithromycin. Chest. 2002;121(6):1782-1788. doi:10.1378/chest.121.6.1782 
13. Hahn DL. Treatment of Chlamydia pneumoniae infection in adult asthma: a before-after trial. J Fam Pract. 1995;41:345-351.

14. World Medical Association. World medical association declaration of Helsinki: ethical principles for medical research involving human subjects. JAMA. 2013;310(20):2191-2194. doi:10.1001/ jama.2013.281053

15. Fuhlbrigge A, Peden D, Apter AJ, et al. Asthma outcomes: exacerbations. J Allergy Clin Immunol. 2012;129(3 Suppl):S34-S48. doi:10.1016/j.jaci.2011.12.983

16. Nathan RA, Sorkness CA, Kosinski M, et al. Development of the asthma control test: a survey for assessing asthma control. J Allergy Clin Immunol. 2004;113(1):59-65. doi:10.1016/j.jaci.2003.09.008

17. Hahn DL. Infectious asthma: a reemerging clinical entity? J Fam Pract. 1995;41(2):153-157.

18. Hahn DL, Peeling RW, Dillon E, McDonald R, Saikku P. Serologic markers for Chlamydia pneumoniae in asthma. Ann Allergy Asthma Immunol. 2000;84(2):227-233. doi:10.1016/S1081-1206(10)62760-3

19. Schatz M, Kosinski M, Yarlas AS, Hanlon J, Watson ME, Jhingran P. The minimally important difference of the asthma control test. $J$ Allergy Clin Immunol. 2009;124(4):719-723 e1. doi:10.1016/j. jaci.2009.06.053

20. Alshabanat A, Zafari Z, Albanyan O, Dairi M, FitzGerald JM, Short P. Asthma and COPD Overlap Syndrome (ACOS): a systematic review and meta analysis. PLoS One. 2015;10(9):e136065. doi:10.1371/journal.pone.0136065

21. Herland K, Akselsen J-P, Skjønsberg OH, Bjermer L. How representative are clinical study patients with asthma or COPD for a larger "real life" population of patients with obstructive lung disease? Respir Med. 2005;99(1):11-19. doi:10.1016/j.rmed.2004.03.026

22. Burrows B, Knudson RJ, Leibowitz M. The relationship of childhood respiratory illness to adult obstructive airway disease. Am Rev Respir Dis. 1977;115:751-760. doi:10.1164/arrd.1977.115.5.751

23. Dodge R, Burrows B, Lebowitz MD, Cline MG. Antecedent features of children in whom asthma develops during the second decade of life. J Allergy Clin Immunol. 1993;92:744-749. doi:10.1016/00916749(93)90018-B

24. Lebowitz MD, Burrows B. The relationship of acute respiratory illness history to the prevalence and incidence of obstructive lung disorders. Am J Epidemiol. 1977;105:544-554. doi:10.1093/oxfordjournals.aje.a112418

25. Rantala A, Jaakkola JJ, Jaakkola MS. Respiratory infections precede adult-onset asthma. PLoS One. 2011;6(12):e27912. doi:10.1371/journal.pone.0027912

26. Steel HC, Theron AJ, Cockeran R, Anderson R, Feldman C. Pathogenand host-directed anti-inflammatory activities of macrolide antibiotics. Mediators Inflamm. 2012;2012:584262. doi:10.1155/2012/584262

27. Hiles SA, McDonald VM, Guilhermino M, Brusselle GG, Gibson PG. Does maintenance azithromycin reduce asthma exacerbations? An individual participant data meta-analysis. Eur Respir J. 2019;54 (5):1901381. doi:10.1183/13993003.01381-2019
28. Kuzin II, Snyder JE, Ugine GD, et al. Tetracyclines inhibit activated B cell function. Int Immunol. 2001;13(7):921-931. doi:10.1093/ intimm/13.7.921

29. Wang S-P, Grayston JT. Population prevalence antibody to Chlamydia pneumoniae, strain TWAR. In: Bowie WR, Caldwell HD, Jones RP, editors. Proceedings of the Seventh International Symposium on Human Chlamydial Infections. Cambridge: Cambridge University Press; 1990:402-405.

30. Parrott GL, Kinjo T, Fujita J. A compendium for Mycoplasma pneumoniae. Front Microbiol. 2016;7:513. doi:10.3389/fmicb.2016.00513

31. Dowell SF, Peeling RW, Boman J, et al. Standardizing Chlamydia pneumoniae assays: recommendations from the centers for disease control and prevention (USA) and the Laboratory Centre for Disease Control (Canada). Clin Infect Dis. 2001;33(4):492-503. doi:10.1086/ 322632

32. Aaron SD, Vandemheen KL, FitzGerald JM, et al. Reevaluation of diagnosis in adults with physician-diagnosed asthma. JAMA. 2017;317(3):269-279. doi:10.1001/jama.2016.19627

33. Carter JD, Espinoza LR, Inman RD, et al. Combination antibiotics as a treatment for chronic Chlamydia-induced reactive arthritis: a double-blind, placebo-controlled, prospective trial. Arthritis Rheum. 2010;62(5):1298-1307. doi:10.1002/art.27394

34. Kvien TK, Gaston JSH, Bardin T, et al. Three month treatment of reactive arthritis with azithromycin: a EULAR double blind, placebo controlled study. Ann Rheum Dis. 2004;63:1113-1119. doi:10.1136/ ard.2003.010710

35. Hahn DL, Schure A, Patel K, Childs T, Drizik E, Webley W. Chlamydia pneumoniae-specific IgE is prevalent in asthma and is associated with disease severity. PLoS One. 2012;7(4):e35945. doi:10.31371/journal.pone.0035945

36. Hahn DL. Chlamydia pneumoniae and chronic asthma: updated systematic review and meta-analysis of population attributable risk. PLoS One. 2021;16(4):e0250034. doi:10.1371/journal.pone.0250034

37. Hahn DL, Plane MB, Mahdi OS, Byrne GI. Secondary outcomes of a pilot randomized trial of azithromycin treatment for asthma. PLoS Clin Trials. 2006;1(2):e11. doi:10.1371/journal.pctr.0010011

38. Rahman KS, Kaltenboeck B. Multi-peptide ELISAs overcome crossreactivity and inadequate sensitivity of conventional Chlamydia pneumoniae serology. Sci Rep. 2019;9(1):15078. doi:10.1038/ s41598-019-51501-5

39. Peters J, Singh H, Brooks EG, et al. Persistence of communityacquired respiratory distress syndrome toxin-producing Mycoplasma pneumoniae in refractory asthma. Chest. 2011;140(2):401-407. doi:10.1378/chest.11-0221

40. Hahn D. When guideline treatment of asthma fails, consider a macrolide antibiotic. J Fam Pract. 2019;68(10):536-545.

\section{Publish your work in this journal}

The Journal of Asthma and Allergy is an international, peer-reviewed open-access journal publishing original research, reports, editorials and commentaries on the following topics: Asthma; Pulmonary physiology; Asthma related clinical health; Clinical immunology and the immunological basis of disease; Pharmacological interventions and new therapies. The manuscript management system is completely online and includes a very quick and fair peer-review system, which is all easy to use. Visit http://www.dovepress.com/testimonials.php to read real quotes from published authors. 